\title{
JORNAL DE
}

POLÍTICAS EdUCACIONAIS

\section{Qualidade educacional e Ideb: uma análise dos Planos de Educação de Goiás e de São Luís de Montes Belos em contraponto à percepção dos professores dessa Rede Municipal de Ensino}

\section{Educational quality and Ideb: an analysis of the Education Plans of Goiás and São Luís de Montes Belos in counterpoint to the teachers perception of this Municipal Education System}

Calidad educativa y Índice de Desarrollo de la Educación Básica (Ideb): un análisis de los Planes de Educación de Goiás y de São Luís de Montes Belos en contrapunto a la percepción de los profesores de esa Red Municipal de Enseñanza

Citação: ALVES, E. F.; ASSIS, L. M. Qualidade educacional e Ideb: uma análise dos Planos de Educação de Goiás e de São Luís de Montes Belos em contraponto à percepção dos professores dessa Rede Municipal de Ensino. Jornal de Políticas Educacionais. V. 12, n. 7. Maio de 2018.

Resumo: 0 presente trabalho visa discutir o conceito de qualidade da educação a partir da adoção das avaliações em larga escala no Brasil, mais precisamente com a implementação do Índice de Desenvolvimento da Educação Básica (Ideb). Metodologicamente, utilizou-se de pesquisa bibliográfica, documental e de estudo de campo efetivado com a aplicação de questionários com questões abertas a professores do $5^{\underline{0}}$ ano do ensino fundamental. Este trabalho analisa a concepção gerencialista de qualidade em contraposição à concepção de qualidade socialmente referenciada; amplia a discussão com a análise da presença do Ideb nos planos decenais de educação de âmbito nacional, estadual de Goiás e municipal de São Luís de Montes Belos-GO; e, por fim, apresenta e discute a percepção de professores de uma rede municipal

\footnotetext{
${ }^{1}$ Mestre em Educação/UFG. Doutorando em Educação pelo Programa de Pós-Graduação em Educação da UFG. Professor da rede estadual de Goiás e municipal de São Luís de Montes Belos. E-mail: edson.belos@ gmail.com ${ }^{2}$ Doutora em Educação/UFG. Professora do Programa de Pós-Graduação em Educação da Universidade Federal de Goiás. E-mail: luciamariadeassis@gmail.com
} 
ALVES, E. F.; ASSIS, L. M. Qualidade educacional e Ideb: uma análise dos Planos de Educação de Goiás e de São Luís de Montes Belos em contraponto à percepção dos professores dessa Rede Municipal de

Ensino.

de ensino a respeito do índice, analisando as implicações que o indicador tem trazido para o trabalho docente. Fundamenta-se em autores como Dourado e Oliveira (2009), Afonso (2000; 2010), Azevedo (2014), Freitas (2013), Gatti (2013), Assis (2016) Dourado (2016) e outros. 0 estudo dos planos estadual e municipal aponta para a reprodução do texto do PNE nos planos subnacionais enquanto que as falas dos docentes expressam as angústias que o Ideb tem acarretado ao trabalho pedagógico, pressionados pelo ranqueamento e necessidade de treinar continuamente os alunos para desempenho positivo no índice, num processo de responsabilização e culpabilização docente.

Palavras-chave: Qualidade da educação; Ideb; PNE 2014-2024; Plano Estadual e Municipal de Educação; Trabalho docente.

Abstract: This paper aims to discuss the concept of quality of education based on the adoption of largescale evaluations in Brazil, more precisely with the implementation of the Índice de Desenvolvimento da Educação Básica (Ideb) [Basic Education Development Index]. Methodologically, it was used bibliographical, documentary and field researches carried out with the application of questionnaires with open questions to fifth grade of the elementary education teachers. This paper analyzes the managerialist conception of quality as opposed to the conception of socially referenced quality; amplifies the discussion with the analysis of Ideb's presence in the decennial plans of education at national level, in the state of Goiás and in the city of São Luís de Montes Belos-GO; and, lastly, presents and discusses the perception of teachers of a municipal education network regarding the index, analyzing the implications that the indicator has been bringing to the teaching work. It is based on authors such as Dourado and Oliveira (2009), Afonso (2000; 2010), Azevedo (2014), Freitas (2013), Gatti (2013), Assis (2016) Dourado (2016) and others. The study of the state and municipal plans points to the reproduction of the text of the PNE [Plano Nacional de Educação - National Education Plan] in the subnational plans, while the teachers' statements express the anguish that the Ideb has brought to the pedagogical work. They are pressured by the ranking and by the need to continuously train the students for positive performance in the index, in a process to blame and hold teachers accountable.

Keywords: Education quality; Ideb; PNE 2014-2024; State and Municipal Education Plan; Teaching work.

Resumen: El presente trabajo visa discutir el concepto de calidad de la educación a partir de la adopción de las evaluaciones en larga escala en Brasil, más precisamente con la implementación del Índice de Desarrollo de la Educación Básica (Ideb). Metodológicamente, se utilizó la investigación bibliográfica, documental y de estudio de campo efectuado con la aplicación de cuestionarios con cuestiones abiertas a profesores del 5o año de la enseñanza fundamental. Este trabajo analiza la concepción gerencialista de calidad en contraposición a la concepción de calidad socialmente referenciada; amplía la discusión con el análisis de la presencia de Ideb en los planes decenales de educación en ámbito nacional, estatal de Goiás y municipal de São Luís de Montes Belos-GO; y, por fin, presenta y discute la percepción de profesores de una red municipal de enseñanza a respeto del índice, analizando las implicaciones que el indicador ha traído para el trabajo docente. Se fundamenta en autores como Dourado y Oliveira (2009), Afonso (2000; 2010), Azevedo (2014), Freitas (2013), Gatti (2013), Assis (2016) Dourado (2016) y otras. El estudio de los planes estatales y municipal apunta para la reproducción del texto del PNE en los planes subnacionales mientras las hablas de los docentes expresan las angustias que el Ideb ha provocado en el trabajo pedagógico, presionados por la clasificación y necesidad de entrenar continuamente a los alumnos para desempeño positivo en el índice, en un proceso de responsabilización y culpabilización docente.

Palabras clave: Calidad de la educación; Ideb; PNE 2014-2024; Plan Estatal y Municipal de Educación; Trabajo docente.

\section{Introdução}

Discutir a qualidade da educação é um exercício que exige reflexão acerca dos fatores internos e externos que determinam o que vem a ser essa tal qualidade, e este é o ponto inicial deste trabalho. Na primeira parte, discute-se o conceito de qualidade na perspectiva gerencialista incorporada aos sistemas de ensino em detrimento da qualidade socialmente referenciada defendida em instâncias de debate, como as Conferências 
ALVES, E. F.; ASSIS, L. M. Qualidade educacional e Ideb: uma análise dos Planos de Educação de Goiás e de São Luís de Montes Belos em contraponto à percepção dos professores dessa Rede Municipal de

Ensino.

Nacionais de Educação (Conae) realizadas em 2010 e 2014. No contexto das avaliações em larga escala como instrumentos de verificação da qualidade do ensino, é apresentado o Índice de Desenvolvimento da Educação Básica (Ideb) como o padrão de qualidade referendado pelos princípios empresariais e pelas políticas públicas vigentes. Como contraponto, discute-se a concepção de qualidade da educação socialmente referenciada, proposta por educadores e movimentos sociais progressistas.

Considerando o peso que o Ideb assumiu nos últimos anos, ao ponto de ser instituído como política de Estado no Plano Nacional de Educação (PNE 2014 - 2024), na segunda parte, este estudo se propõe a problematizar a presença do indicador no PNE e nos planos subnacionais. Toma-se como objetos e recorte o Plano Estadual de Educação de Goiás (PEE) e o Plano Municipal de Educação de São Luís de Montes Belos (PME), visando responder a questão: o Ideb está contemplado nos planos decenais indicados, compreendendo estes documentos como o epicentro das políticas públicas (DOURADO, 2016)?

Na terceira parte, são apresentadas as percepções dos professores sobre o Ideb utilizando-se, para isso, como metodologia, a aplicação de questionários elaborados com questões abertas. Foram ouvidos oito professores, todos servidores efetivos, o que equivale a $66 \%$ dos profissionais da rede municipal de ensino de São Luís de Montes Belos que atuam em turmas do $5^{0}$ ano do ensino fundamental, contemplando sete instituições da rede que correspondem a 87\% das unidades escolares urbanas do município. Buscou-se identificar como o Ideb está modificando o trabalho docente e como os professores da amostra estão lidando com os resultados deste índice no cotidiano escolar, tendo em vista o peso atribuído a esse indicador nos planos decenais de educação.

\section{Qualidade em tempos de Ideb e qualidade social da educação}

0 termo qualidade, que procede do latim qualitatem, compreende um conceito subjetivo, que implica reconhecer as percepções sociais dos sujeitos, o que convém falar em qualidades. Assim, quando nos referimos à qualidade da educação,

Compreende-se então a qualidade com base em uma perspectiva polissêmica, em que a concepção de mundo, de sociedade e de educação evidencia e define os elementos para qualificar, avaliar e precisar a natureza, as propriedades e os atributos desejáveis de um processo educativo de qualidade social. (DOURADO; OLIVEIRA, 2009, p. 202). 
Definir qualidade em educação é um movimento complexo que remete ao contexto sócio-histórico e às necessidades da população inserida em um determinado contexto cultural, social e econômico. Tal movimento implica em pensar nas condições de processamento das vontades políticas, éticas, da formação humana e para o mundo do trabalho, visando uma formação do sujeito que possibilite a sua inserção na sociedade por meio de currículos que contemplem as múltiplas e diversas manifestações culturais e artísticas, a ciência, o lazer, as múltiplas linguagens, as novas tecnologias, etc. Nessa perspectiva,

Quanto à qualidade, trata-se de conceito complexo que pressupõe parâmetros comparativos para o que se julga uma boa ou má qualidade nos fenômenos sociais. Como atributo, a qualidade e seus parâmetros integram sempre o sistema de valores da sociedade e sofrem variações de acordo com cada momento histórico, de acordo com as circunstâncias temporais e espaciais. (BRASIL, 2014a, p. 64).

Nas últimas três décadas, no Brasil, a definição de qualidade da educação tem se fundado por escolhas de quase-mercado (AFONSO, 2010), ou seja, nos conceitos de eficiência, eficácia, meritocracia, responsabilização, privatização, produtividade, gestão por resultados, entre outros. A qualidade da educação básica tem se manifestado na definição de metas objetivas a serem perseguidas pelos sistemas de ensino, através do desempenho em avaliações estandardizadas que focam apenas nos resultados. Trata-se de um padrão de qualidade gerencialista, segundo o qual os resultados em avaliações aplicadas em larga escala se tornam o referencial da "qualidade da educação"; ou seja, terá qualidade aquela escola que atingir as notas indicadas em escalas de proficiência definidas no centro das políticas educacionais, com foco quase que exclusivo no desempenho de estudantes em provas aplicadas periodicamente.

A qualidade da educação na perspectiva gerencialista tomou corpo no Estado brasileiro com a ampliação das ideias neoliberais que passaram a orientar as ações políticas pós anos 1980. Com a criação do Sistema de Avaliação da Educação Básica (Saeb), em 1990, assistiu-se à implantação de um modelo, centralizado no governo federal, de monitoramento e diagnóstico da referida "qualidade da educação", que passou a ser mensurada através de testes estandardizados aplicados de forma amostral em escolas públicas do país. 
ALVES, E. F.; ASSIS, L. M. Qualidade educacional e Ideb: uma análise dos Planos de Educação de Goiás e de São Luís de Montes Belos em contraponto à percepção dos professores dessa Rede Municipal de Ensino.

Em 2005, com a criação da Prova Brasil, a avaliação bienal passou de amostral para censitária e ampliou-se o escopo gerencialista da "qualidade da educação", cuja abrangência do exame permitiu identificar os sujeitos e as instituições participantes por meio da aplicação de exames padronizados que passaram a mensurar o domínio dos conteúdos dos discentes em Língua Portuguesa (leitura, interpretação de textos) e Matemática (cálculos e resolução de problemas). Com essa nova configuração, criou-se a potencialidade de responsabilizar cada unidade escolar por seu próprio rendimento, principalmente com a estratégia de publicização dos resultados, utilizando como argumento o controle social e a prestação de contas (accountability) à sociedade dos serviços educacionais ofertados. Dessa forma, a "divulgação dos resultados da Prova Brasil fomentou comportamentos orientados para a comparação, competição, premiação, punição" (FREITAS, 2013, p. 74). Assim, a melhora da qualidade da educação aconteceria mediante o processo de concorrência entre as unidades de ensino. Escolas com rendimentos melhores tenderiam a atrair alunos com melhores condições de desempenho.

Este processo de responsabilização foi ampliado com a criação, em 2007, do Ideb, que delimitou para cada unidade escolar, cada município, estado e para o país, as metas objetivas numa escala ascendente a serem atingidas a cada dois anos até o ano de 2021, quando se prevê a média 6.0 (anos iniciais do ensino fundamental), atingindo o mesmo nível dos países desenvolvidos.

O Ideb foi composto com os resultados das proficiências medidas na Prova Brasil e dados do fluxo escolar - taxa de aprovação divulgada pelo Censo Escolar, objetivando “a) detectar escolas e/ou redes de ensino cujos alunos apresentem baixa performance e b) monitorar a evolução temporal do desempenho dos alunos dessas escolas e/ou redes de ensino" (FERNANDES, 2007, p. 8). A par dessa composição, Freitas (2013, p. 75) analisa que "operando somente com os indicadores do fluxo escolar e do desempenho cognitivo dos alunos, o Ideb acaba contribuindo para que a busca de melhoria da qualidade do ensino seja vista e enfrentada de forma estreita", pois desconsidera os contextos internos e externos à escola.

Contando com um aparato midiático, o Ideb tornou-se a principal referência de "qualidade" da educação básica brasileira, construindo no imaginário popular a compreensão de que “a 'boa escola' passou a ser aquela que melhor prepara os alunos 
ALVES, E. F.; ASSIS, L. M. Qualidade educacional e Ideb: uma análise dos Planos de Educação de Goiás e de São Luís de Montes Belos em contraponto à percepção dos professores dessa Rede Municipal de

Ensino.

para os exames nacionais, que afinal de contas é o que irá indicar se houve ou não 'melhoria da qualidade' do ensino, apresentado sob a forma de um índice e exposto em gráficos na portas das escolas" (ASSIS, 2016, p. 15), o que favorece o ranqueamento e a competição entre as instituições de ensino. Num mesmo sistema de ensino, encontrar-seão unidades escolares disputando a preferência da clientela utilizando-se de propaganda com base em seus indicadores.

Com tais características e peso midiático, o Ideb representou a corporificação do

Estado Avaliador no sistema educacional brasileiro no que tange à educação básica. Explica Afonso (2000) que,

Esta expressão quer significar, em sentido amplo, que o Estado vem adoptando um ethos competitivo, neodarwinista, passando a admitir a lógica do mercado, através da importação para o domínio público de modelos de gestão privada, com ênfase nos resultados ou produtos dos sistemas educativos. [...] Neste sentido, por exemplo, diminuir as despesas públicas exigiu não só a adopção de uma cultura gestionária (ou gerencialista) no sector público, como induziu a criação de mecanismos de controlo e responsabilização mais sofisticados. (p. 49).

A Prova Brasil e o Ideb são exemplos desses mecanismos de controle e responsabilização mais sofisticados empregados pelo Estado Avaliador brasileiro. Gatti (2013) colabora com essa análise ao afirmar que

[...] tem-se observado que tanto o indicador, quanto as avaliações, se tornaram o carro-chefe das ações políticas em educação, muito especialmente em nível federal. [...] isso indica uma perspectiva produtivista em educação [...] e aponta para um modelo gerencialista que passa a modelar as reformas educacionais, com foco apenas nos resultados de rendimento escolar dos alunos, conduzindo a um certo reducionismo curricular com co-centramento em duas áreas curriculares, apenas: leitura e matemática. (p. 58).

Outro fator refere-se à responsabilização dos docentes pelos resultados. Ao localizar "a nota" por unidade escolar, amplia-se a pressão sobre a figura do professor quanto aos resultados, pois o que está em jogo no Ideb são as taxas de aprovação, reprovação e evasão (fluxo escolar), e de desempenho (proficiência na Prova Brasil). Ou seja, o índice leva em consideração, de forma restrita, apenas fatores ligados ao rendimento escolar e, de certa forma, ligados ao impacto do trabalho docente: se o professor ensinar de forma eficiente e eficaz, o aluno aprenderá, terá notas boas na Prova Brasil e também passará de ano, logo, a escola terá um bom Ideb. 
ALVES, E. F.; ASSIS, L. M. Qualidade educacional e Ideb: uma análise dos Planos de Educação de Goiás e de São Luís de Montes Belos em contraponto à percepção dos professores dessa Rede Municipal de

Ensino.

Ao eleger somente os dados da média do desempenho dos estudantes e os dados do fluxo escolar do ano anterior como fatores de composição do índice, o Ideb ignora os contextos socioeconômicos e culturais dos estudantes, as condições de trabalho docente e as características da gestão escolar, apesar de informações correlatas serem coletadas em questionários de fatores associados ao desempenho, instrumentos que são subutilizados.

Além da responsabilização pelos resultados, a avaliação em larga escala propicia a adoção, pelos governos, de bonificações e/ou punições aos docentes, gestores e estudantes. Os governos, inspirados nos modelos de gestão pública que adotam o estímulo à meritocracia, ao divulgarem os resultados individualizados, estimulam uma perversa competição entre escolas e uma responsabilização indevida aos professores por eventuais fracassos dos alunos ou não cumprimento das metas estabelecidas. Como consequência, "a responsabilização baseada na lógica da culpabilização docente e da escola corrompe e degrada o trabalho docente, posto que altera a forma como os professores pensam sobre o que fazem e como se relacionam com os colegas e com os alunos" (RICHTER; SOUZA; SILVA, 2015, p. 612).

Pelo exposto, o Ideb, mesmo com suas limitações, coroou a "qualidade" numa perspectiva gerencialista na educação básica, numa concepção que vai contra o proposto pelos movimentos sociais progressistas e de educadores manifestos nas Conaes realizadas em 2010 e 2014, que defendiam uma educação de qualidade socialmente referenciada.

Na compreensão de uma educação com qualidade social, amplia-se o conceito de qualidade não se restringindo apenas a um aspecto que, no caso do Ideb, limitou-se ao rendimento e fluxo escolar. A qualidade da educação, numa perspectiva ampliada, segundo Dourado e Oliveira (2009, p. 205), “envolve dimensões extra e intraescolares e, nessa ótica, devem se considerar os diferentes atores, a dinâmica pedagógica, [...] bem como os diferentes fatores extraescolares que interferem direta ou indiretamente nos resultados educativos".

Na perspectiva da Conae/2014, educação com qualidade social

[...] visa à emancipação dos sujeitos sociais e não guarda em si mesma um conjunto de critérios que a delimite. É a partir da concepção de mundo, ser humano, sociedade e educação que a escola procura desenvolver conhecimentos, habilidades e atitudes para encaminhar a forma pela qual o indivíduo vai se relacionar com a sociedade, com a natureza e consigo mesmo. A 'educação de qualidade' é aquela que contribui com a formação dos estudantes nos aspectos humanos, sociais, culturais, filosóficos, 
científicos, históricos, antropológicos, afetivos, econômicos, ambientais e políticos, para o desempenho de seu papel de cidadão no mundo, tornando-se, assim, uma qualidade referenciada no social. Nesse sentido, o ensino de qualidade está intimamente ligado à transformação da realidade na construção plena da cidadania e na garantia aos direitos humanos. (BRASIL, 2014a, p. 65-66).

A concepção de qualidade nesta lógica dá-se de forma ampliada, visando a formação histórica, crítica e humanística dos sujeitos, o que implica que os critérios de avaliação devem também ser ampliados, pois, "a qualidade da educação, portanto, não se circunscreve a médias, em um dado momento, a um aspecto, mas configura-se como processo complexo e dinâmico, margeado por um conjunto de valores como credibilidade, comparabilidade, entre outros" (DOURADO; OLIVEIRA, 2009, p. 207).

Definir qualidade da educação, por suas várias dimensões, torna-se tarefa reflexiva constante e empreende trabalho de educadores, movimentos sociais, classe política e demais agentes sociais. É tarefa de Estado, numa concepção ampliada, de articulação entre sociedade civil e política, pois trata-se de um campo em disputas marcado por uma sociedade cindida em classes antagônicas, que apresenta e reforça uma vergonhosa desigualdade social e econômica e que, por isso, ainda não possui uma democracia plena. É nesse campo de disputas que se colocam os Planos Nacional, Estaduais e Municipais de Educação.

\section{Ideb: o que dizem os Planos de Educação}

O PNE (2014-2024), Lei 13.005, de 25 de junho de 2014, carrega algumas contradições expressivas no referente aos conceitos de qualidade da educação estabelecidos em diversas metas e estratégias. Os movimentos de discussão e aprovação do PNE representaram, conforme Assis (2016, p. 4), o embate entre dois campos de disputa, "o campo educacional que luta pela formulação de uma lei que contemple os interesses construídos no coletivo dos movimentos sociais e o campo econômico, que impõe uma agenda afinada com os interesses do 'capital' ou das classes hegemônicas".

Perante esses campos em disputa, o legislador fez uma escolha clara: definiu como parâmetro de qualidade o Ideb, conforme consta na referida Lei, que especifica os objetos do Sistema Nacional de Avaliação da Educação Básica:

Art. 11. O Sistema Nacional de Avaliação da Educação Básica, coordenado pela União, em colaboração com os estados, o Distrito Federal e os 
ALVES, E. F.; ASSIS, L. M. Qualidade educacional e Ideb: uma análise dos Planos de Educação de Goiás e de São Luís de Montes Belos em contraponto à percepção dos professores dessa Rede Municipal de

Ensino.

municípios, constituirá fonte de informação para a avaliação da qualidade da educação básica e para a orientação das políticas públicas desse nível de ensino.

$\S 1^{\circ} 0$ sistema de avaliação a que se refere o caput produzirá, no máximo a cada dois anos:

I - indicadores de rendimento escolar, referentes ao desempenho dos(as) estudantes apurado em exames nacionais de avaliação, com participação de pelo menos oitenta por cento dos(as) alunos(as) de cada ano escolar periodicamente avaliado em cada escola, e aos dados pertinentes apurados pelo censo escolar da educação básica; (BRASIL, 2014b, p. 47. Grifos nossos).

A opção pelo Ideb como indicador de qualidade fica mais evidente na Meta 7, que estabelece o índice como parâmetro de qualidade da educação e define médias nacionais como metas a atingir, previstas até o ano de 2021. Segundo Dourado (2016),

A Meta 7 propõe fomentar a qualidade da educação básica por meio da melhoria do fluxo escolar e da aprendizagem, tendo por eixo atingir as metas nacionais para o Ideb. Esta meta é bastante emblemática e tem como eixo fundante os exames de larga escala e o fluxo escolar. Trata-se de um caso típico de garantia, no texto legal, de política governamental, centrada em exames e índices (p. 29).

Com essa concepção, o PNE (2014-2024) “aponta para a legitimação, consolidação e fortalecimento do Ideb, ao torná-lo um instrumento de política do Estado" (FREITAS, 2013, p. 79). 0 índice deixa a esfera de programa de governo e é conduzido como uma ação do Estado brasileiro, contemplado na forma de Lei no plano decenal da educação.

Quanto às contradições, Assis (2016) analisa que ficou difícil defender o PNE (2014-2024) por ele utilizar os resultados dos exames nacionais em larga escala como indicador de qualidade da educação, pois,

[...] ao mesmo tempo em que prevê a "superação das desigualdades educacionais, com ênfase na promoção da cidadania e na erradicação de todas as formas de discriminação" e um "Sistema Nacional de Avaliação da Educação Básica, coordenado pela União, em colaboração com os estados, o Distrito Federal e os municípios, constituirá fonte de informação para a avaliação de qualidade de educação básica e para a orientação das políticas públicas desse nível de ensino", também prevê a elaboração e a divulgação de índices para avaliação da qualidade, como o Índice de Desenvolvimento da Educação Básica. (p. 8). 
ALVES, E. F.; ASSIS, L. M. Qualidade educacional e Ideb: uma análise dos Planos de Educação de Goiás e de São Luís de Montes Belos em contraponto à percepção dos professores dessa Rede Municipal de

Ensino.

Fica evidente a opção do legislador por uma referência de qualidade focada no

Ideb e nos conceitos inerentes a ele como a meritocracia, a responsabilização e o ranqueamento. Nesse contexto,

As orientações para o sistema de avaliação privilegiam a estandardização de resultados, mostrando a forte interferência no PNE e na política educacional brasileira dos padrões de qualidade estabelecidos para as sociedades de mercado, segundo parâmetros globalizados. Ao estimular o favorecimento de escolas com melhor desempenho, premiando-as, a tendência é que sejam penalizadas aquelas unidades que, de princípio, necessitariam de maior estímulo e apoio em termos de recursos financeiros. Nesse quadro, avaliar a qualidade por meio de índices, como o Índice de Desenvolvimento da Educação Básica (Ideb), restringe aprendizagens a terminalidades, sem considerar processos. (AZEVEDO, 2014, p. 276).

Portanto, mesmo com todo movimento e todas possibilidades apontadas nas Conaes/2010 e 2014 e, em tese, contando com um governo progressista no poder, o que se percebe no PNE (2014-2024) é a opção por um parâmetro de qualidade focado nos moldes gerencialistas, que

[...] ao vincular o acompanhamento e a promoção da qualidade da educação no Brasil aos indicadores de desempenho dos estudantes mensurados pelo Ideb, o PNE reforçou uma política de matriz neoliberal, que promove a classificação e o ranking das escolas, desresponsabiliza os governos quanto ao seu protagonismo no investimento de esforços para a solução dos problemas detectados e induz os profissionais da educação a uma atitude de permanente alerta quanto aos resultados do índice. (ASSIS, 2016, p. 11).

Quanto aos planos decenais de estados e municípios, estes entes subnacionais tiveram o prazo de um ano para sua elaboração, em consonância com as diretrizes, metas e estratégias previstas no PNE (2014-2024). Situando o PNE como epicentro das políticas educacionais (DOURADO, 2016), o mesmo conceito se aplica aos planos estaduais e municipais, que congregam o projeto de educação para o decênio através do planejamento num contexto de assimetrias na esfera educacional. Tais planos foram propostos como meios de reagir a condições consideradas insatisfatórias, "voltando-se, pois, para a busca de mudanças na realidade social com base em interpretações e compreensões dessa realidade, o que envolve valores, ideias, concepções políticoideológicas, tudo isso segundo um determinado projeto mais global de sociedade" (AZEVEDO, 2014, p. 266). 
ALVES, E. F.; ASSIS, L. M. Qualidade educacional e Ideb: uma análise dos Planos de Educação de Goiás e de São Luís de Montes Belos em contraponto à percepção dos professores dessa Rede Municipal de

Ensino.

Analisando o PEE do Estado de Goiás, Lei no 18.969, de 22 de julho de 2015, e o

PME do Município de São Luís de Montes Belos-GO, Lei no 2.058, de 24 de junho de 2015, percebe-se que a expressão "em consonância com o PNE" foi contemplada de forma restrita, tendo os entes federados em estudo replicado a Meta 7 do PNE em seus respectivos planos de educação, conforme observado no quadro abaixo:

Quadro 1. Meta e estratégias correspondentes ao Ideb nos planos decenais de educação

\begin{tabular}{|c|c|c|}
\hline PNE 2014/2024 & PEE Goiás (2015) & PME São L. M. Belos (2015) \\
\hline $\begin{array}{l}\text { Meta } 7 \text { - Fomentar a qualidade } \\
\text { da educação básica em todas as } \\
\text { etapas e modalidades, com } \\
\text { melhoria do fluxo escolar e da } \\
\text { aprendizagem de modo a atingir } \\
\text { as seguintes médias nacionais } \\
\text { para o Ideb [...]. } \\
7.6 \text { associar a prestação de } \\
\text { assistência técnica financeira à } \\
\text { fixação de metas intermediárias, } \\
\text { nos termos estabelecidos } \\
\text { conforme pactuação voluntária } \\
\text { entre os entes, priorizando } \\
\text { sistemas e redes de ensino com } \\
\text { Ideb abaixo da média nacional; } \\
\text { 7.36. estabelecer políticas de } \\
\text { estímulo às escolas que } \\
\text { melhorarem o desempenho no } \\
\text { Ideb, de modo a valorizar o } \\
\text { mérito do corpo docente, da } \\
\text { direção e da comunidade escolar. } \\
\text { (BRASIL, 2014). }\end{array}$ & $\begin{array}{l}\text { Meta } 4 \text { - Assegurar até a vigência } \\
\text { final deste Plano a melhoria da } \\
\text { qualidade da Educação Básica } \\
\text { em suas etapas e modalidades e } \\
\text { do fluxo escolar, a partir dos } \\
\text { indicadores das avaliações } \\
\text { externas, incluindo e cumprindo } \\
\text { os índices estabelecidos no } \\
\text { Índice de Desenvolvimento da } \\
\text { Educação Básica - IDEB. } \\
\text { 4.16) estabelecer políticas de } \\
\text { estímulo com critérios pré- } \\
\text { definidos e estabelecidos pelas } \\
\text { mantenedoras às escolas que } \\
\text { melhorarem o desempenho no } \\
\text { Índice de Desenvolvimento da } \\
\text { Educação Básica - IDEB. (GOIÁS, } \\
\text { 2015). }\end{array}$ & $\begin{array}{l}\text { Meta } 7 \text { - Fomentar a qualidade } \\
\text { da Educação Básica, com } \\
\text { melhoria no fluxo escolar e da } \\
\text { aprendizagem de modo a } \\
\text { colaborar para o alcance das } \\
\text { Médias projetadas para o Índice } \\
\text { de Desenvolvimento da } \\
\text { Educação Básica no município. } \\
\text { 7.6) assegurar, a assistência } \\
\text { técnica financeira, conforme a } \\
\text { estratégia } 7.6 \text { do PNE, às escolas } \\
\text { da redes de ensino do município, } \\
\text { com o IDEB abaixo da média } \\
\text { nacional; (SÃO LUÍS DE MONTES } \\
\text { BELOS, 2015). }\end{array}$ \\
\hline
\end{tabular}
Fonte: Brasil (2014), Goiás (2015) e São Luís de Montes Belos (2015).

Conforme pode ser observado, tanto o Estado de Goiás como o Município de São Luís de Montes Belos ratificaram em seus planos decenais o que fora exposto no PNE (2014-2024): a opção do Ideb enquanto indicador de qualidade. O mesmo pode ser destacado na análise das estratégias correlatas, que apresentam planos como reprodução do correspondente nacional; ou seja, no tocante à Meta 7, os planos subnacionais são praticamente cópias do Plano Nacional. Em tese, tanto o Estado de Goiás quanto o Município de São Luís de Montes Belos não utilizaram a oportunidade, no momento de discussões, elaboração e aprovação dos respectivos planos, de colocarem suas próprias compreensões quanto à qualidade da educação desejada, a não ser que a qualidade expressa via Ideb seja, de fato, a qualidade esperada, a meta a ser perseguida pelas comunidades e administradores locais. 
ALVES, E. F.; ASSIS, L. M. Qualidade educacional e Ideb: uma análise dos Planos de Educação de Goiás e de São Luís de Montes Belos em contraponto à percepção dos professores dessa Rede Municipal de

Ensino.

Mas duas ausências chamam atenção: no caso do PEE de Goiás, suprimiu-se o equivalente à estratégia 7.6 do PNE: apoio financeiro às unidades com baixo Ideb. Quanto ao PME de São Luís de Montes Belos, não há estratégia equivalente à 7.36: bonificação às escolas que atinjam as metas do índice. 0 que tais ausências significam? A esse respeito, pode-se formular algumas hipóteses, como, por exemplo, o poder público não assumir responsabilidades pelos resultados da escola. "Para a escola, todo o rigor; para o Estado, a relativização 'do que é possível fazer'” (FREITAS, 2007, p. 975).

Outro aspecto que chama a atenção é o fato de tanto o estado quanto o município em análise possuírem sistemas próprios de avaliações externas e estes não figurarem nas estratégias correlatas à melhoria da qualidade da educação. Na rede estadual de educação há o Sistema de Avaliação Educacional do Estado de Goiás (Saego), criado em 2011, e na rede municipal de educação há o Sistema Municipal de Avaliação Externa (Simae), criado em 2008.

O Saego, ou "Prova Goiás", é feito nos moldes da Prova Brasil, mas com periodicidade anual abrangendo as disciplinas de Língua Portuguesa e Matemática, sendo avaliadas todas as turmas de $2^{\circ}$, $5^{\circ}$ e $9^{\circ}$ ano do ensino fundamental e $3^{\circ}$ série do ensino médio. A partir dos resultados do Saego, é produzido o Índice de Desenvolvimento da Educação Goiana (Idego), com metas anuais a serem atingidas por escola (GOIÁS, 2013). 0 Simae é feito anualmente, contemplando todos os componentes curriculares e aplicado em todas as séries do ensino fundamental (SÃO LUÍS DE MONTES BELOS, 2016). A ausência do Saego e do Simae reforçam a tese de planos construídos como cópias do Plano Nacional e não como expressão das potencialidades, análises e escolhas locais. Dessa forma, "ao fazer a escolha de estabelecer parâmetros de avaliação da qualidade educacional em índices médios de desempenho dos estudantes em provas padronizadas nacionais, promove-se um reducionismo na análise do sistema" (ASSIS, 2016, p. 15. Grifos nossos).

Portanto, os planos estadual de Goiás e municipal de São Luís de Montes Belos dizem o mesmo que o PNE (2014-2024). Ratifica-se a opção pelo Ideb e pelas provas padronizadas nacionais como indicador de qualidade na perspectiva de mercado em detrimento da concepção de uma qualidade socialmente referenciada, considerando apenas os indicadores de rendimento e fluxo escolar para o cálculo do índice, desprezando os fatores socioeconômicos e culturais associados ao desempenho. 
ALVES, E. F.; ASSIS, L. M. Qualidade educacional e Ideb: uma análise dos Planos de Educação de Goiás e de São Luís de Montes Belos em contraponto à percepção dos professores dessa Rede Municipal de

Ensino.

Constatando-se a opção dos legisladores em adotar o Ideb como referência de qualidade em detrimento de uma qualidade socialmente referenciada, é oportuno questionar o que pensam os professores sobre essa temática, refletindo como o Ideb, desde 2007, vem influenciando as práticas pedagógicas.

\section{Ideb: o que pensam os professores}

Visando analisar a compreensão que os professores de $5^{\underline{0}}$ ano do ensino fundamental têm sobre o Ideb e seus impactos no trabalho docente, foi selecionado como amostra o grupo de professores dessa série escolar da Rede Municipal de Ensino de São Luís de Montes Belos, cidade do interior do Estado de Goiás, local de trabalho de um dos pesquisadores. Considerando a sobrecarga de trabalho dos docentes em final de ano letivo, optou-se como procedimento de recolha de dados o uso de questionário com questões abertas, cujas falas seguem em análise.

As informações dos questionários indicam que 50\% dos professores participantes são favoráveis ao Ideb como instrumento que avalia a qualidade da educação básica, enquanto os outros $50 \%$ não são favoráveis ao índice por ele desconsiderar o contexto da sala de aula e as condições socioeconômicas dos alunos. Todavia, apenas $12,5 \%$ dos professores acreditam que a nota representa com fidedignidade a qualidade do ensino ministrado, 12,5\% acreditam que representa parcialmente, e para 75\% o Ideb não representa a realidade escolar no quesito qualidade.

Questionados sobre como percebem o Ideb, metade dos professores participantes não vê o índice como um indicador positivo, considerando a realidade da escola, principalmente no que tange ao contexto social dos alunos e à responsabilização docente. Nesse sentido, o Ideb é percebido "como uma forma do governo cobrar uma Educação de qualidade sem oferecer subsídios para que ocorra tal qualidade, onde esse resultado recai sobre o professor" (PROF01). Em outras palavras,

Percebo [o índice] como um avaliador do professor e da sua forma de ensinar, sem levar em conta as condições reais do aluno. Nesse caso, a realidade familiar, financeira e psicológica do aluno não é levada em conta. Esse tipo de avaliação é totalmente contrário ao que é 'pregado' para a nossa prática. (PROF02).

Na compreensão dos professores o Ideb é resumido à questão da Prova Brasil. Esta é compreendida numa perspectiva crítica como uma "prova sem valor para a 
ALVES, E. F.; ASSIS, L. M. Qualidade educacional e Ideb: uma análise dos Planos de Educação de Goiás e de São Luís de Montes Belos em contraponto à percepção dos professores dessa Rede Municipal de

Ensino.

educação querendo apenas números para o governo, essa prova não ajuda em nada" (PROF04), pois é vista "como algo completamente fora do contexto real do aluno" (PROF06).

Sobre a forma de trabalhar, os professores participantes reconhecem que a Prova Brasil/Ideb interferiu nas opções pedagógicas, tanto no aspecto metodológico quanto na programação curricular, pois seu foco em leitura e resolução de problemas matemáticos tem provocado o estreitamento curricular, o que aparece na fala dos professores: "Eu me envolvi mais ainda com algumas áreas, como interpretação de texto e situações-problema, já que essas áreas são espelho do Ideb. E tenho mais preocupação em aplicar provas objetivas" (PROF02).

De acordo com os participantes deste estudo, o Ideb tem interferido também na forma de avaliação contínua da aprendizagem dos alunos, transformando esse processo numa espécie de treino para passar na Prova Brasil: "Em anos ímpares, de Prova Brasil, me sinto tendo que trabalhar para a Prova Brasil. Tenho que trabalhar o Programa Curricular, mas sempre priorizando o resultado (positivo) do Ideb. Em outras palavras, passei a treinar os alunos para a Prova Brasil" (PROF03). Segundo Horta Neto (2013, p. 157), treinar para as provas é um dos efeitos destrutivos para a aprendizagem nesse modelo avaliativo, pois tem como consequência o estreitamento do currículo "ao priorizar em sala de aula somente aqueles temas das áreas de matemática e linguagens que serão testados, principalmente às vésperas dos testes [...]".

Para atender a esse cenário de pressão de preparar para a Prova Brasil, os professores têm lançado mão a várias estratégias como, por exemplo: “Faço vários simulados durante o ano, oriento como passar as respostas para o gabarito [cartãoresposta]. Tento sempre conscientizá-los a fazer a prova com responsabilidade" (PROF07). A estratégia do simulado é persistente, sendo utilizada por $100 \%$ dos professores participantes da pesquisa, objetivando treinar os alunos para a prova: "Sempre trabalho voltada para o bom desempenho dos alunos durante todo o ano, mesmo em anos pares. Já em anos de Prova Brasil, fazemos alguns simulados para [eles se] acostumarem" (PROF05). A intenção pretendida é adaptar os alunos à lógica e estrutura da prova, o que, segundo os professores, contribui para um bom desempenho.

Como resultado da política de accountability, os professores do $5^{\underline{o}}$ ano participantes percebem que fazer com que os alunos sejam aprovados na Prova Brasil é 
ALVES, E. F.; ASSIS, L. M. Qualidade educacional e Ideb: uma análise dos Planos de Educação de Goiás e de São Luís de Montes Belos em contraponto à percepção dos professores dessa Rede Municipal de

Ensino.

um trabalho solitário, com a responsabilidade pelos resultados recaindo sobre seus ombros. Assim, quanto ao apoio pedagógico da secretaria do município ou da gestão escolar, nem sempre os professores se sentem amparados com as ajudas necessárias aos alunos para que obtenham o bom desempenho na Prova Brasil, como pode ser percebido nos discursos: i) "Em partes, por meio da gestão escolar até percebo um apoio maior, uma assistência mais precisa, porém sinto ainda desamparada por meio da SME [Secretaria Municipal de Educação]" (PROF08). ii) "Em partes, pois o apoio que recebo é somente imprimir as provas (simulados) que levo" (PROF07). iii) "Não me sinto. Não tem reforço extra, é tudo só comigo" (PROF06).

Com tal arranjo para atender as exigências da Prova Brasil/Ideb, os professores foram questionados se sentem pressão em relação a esse processo de avaliação externa. Todos os participantes declaram sofrer algum tipo de pressão, seja externa ou consigo mesmo, cobrando-se ou sendo cobrados por bons resultados: i) "Sim, pois a Secretaria [Municipal de Educação] cobra os resultados e a competitividade entre as escolas acaba assustando" (PROF01). ii) “É muita pressão. Sinto angústia em anos de Prova Brasil, pois há cobrança por um bom desempenho (boas notas) da escola; passa a ter prioridade a escola e não os alunos" (PROF03). iii) "Muita pressão, não há um dia em que não se fale nisso. Pressão essa que acabo levando aos alunos" (PROF06).

A pressão por bons resultados é consequência da cobrança por manter os bons índices, do ranqueamento das escolas, e para cumprir o currículo estipulado pela Prova Brasil. Essa cobrança gera angústia e tensão e coloca em xeque a capacidade dos professores, num processo massivo de responsabilização e culpabilização.

Parte dos professores requer que os resultados dos exames em larga escala não sejam vistos como um fim em si mesmos, mas analisados considerando o contexto, pois

[...] é preciso reunir, sentar-se verificar os resultados, discuti-los, considerando as realidades social, financeira e cultural da escola e do município. Estas realidades variam de município e de escola e a divulgação dos resultados deve ser feita após análise desses parâmetros. (PROF03).

Os professores foram questionados se o Ideb representa com fidedignidade a qualidade da escola. Pelos discursos apresentados, há uma compreensão mais ampliada de qualidade, não restrita ao resultado da Prova Brasil; vai ao encontro da educação socialmente referenciada, pois a nota da Prova Brasil "representa a nota daquela hora, 
ALVES, E. F.; ASSIS, L. M. Qualidade educacional e Ideb: uma análise dos Planos de Educação de Goiás e de São Luís de Montes Belos em contraponto à percepção dos professores dessa Rede Municipal de Ensino.

que pode ser diferente, deveria era investir no ensino, com menos alunos por sala e investir no social do aluno para que ele não venha para a escola cheio de problemas sociais, o que atrapalha sua aprendizagem" (PROF04). Portanto, o nível socioeconômico é visto como fator que influencia muito no desempenho dos alunos, o que caracteriza o Ideb como um processo avaliativo restrito: "Fazemos muito pelos nossos alunos, mas ainda falta muito. A realidade na qual eles vivem, ou a maioria deles, é dura e triste, e o Ideb não avalia isso e nem ajuda nesse sentido" (PROF02).

Os discursos apresentados caminham na direção da responsabilização dos professores pelo desempenho dos estudantes. E os docentes sentem a pressão e caracterizam esse processo como um movimento solitário, gerando angústia e tensão, tendo que buscar estratégias para que o índice "jamais caia", o que muitas vezes incide também sobre o aluno. Nas respostas, pouco se percebe a responsabilidade da gestão do sistema ou mesmo da escola, o que reforça a tese de que os resultados são, quase que exclusivamente, responsabilidade dos professores que trabalham no $5^{\mathrm{o}}$ ano do ensino fundamental, num processo que não reflete a qualidade real do trabalho construído em sala de aula, conforme apontam os próprios educadores.

\section{Considerações Finais}

A qualidade expressa via Ideb é a qualidade referenciada pelo mercado, com a valorização dos resultados finais em detrimento das condições de trabalho e do contexto socioeconômico e cultural dos alunos. Neste cenário, o que se vê é a responsabilização dos professores e das escolas pelo seu desempenho no índice. Cumprir as metas estabelecidas tornou-se tarefa do professor, pois representa a qualidade da educação ofertada, num contexto em que vigoram a competição, a responsabilização, a premiação e a punição.

Esse modelo de qualidade foi o adotado pelos legisladores ao definir nos Planos Nacional, Estadual e Municipal de Educação o Ideb como sendo o padrão de qualidade. Os planos analisados ratificam essa escolha ao definir a escala do Ideb como uma meta a ser atingida até o ano de 2021, e definem estratégias para atingir tal demanda, muitas vezes marcada pelo ranqueamento das unidades escolares, da promoção de escolas bemsucedidas no Ideb ou de socorro às escolas com baixo desempenho, mostrando que o principal a se fazer é garantir que todas as unidades atinjam o índice. 
ALVES, E. F.; ASSIS, L. M. Qualidade educacional e Ideb: uma análise dos Planos de Educação de Goiás e de São Luís de Montes Belos em contraponto à percepção dos professores dessa Rede Municipal de

Ensino.

Com a valorização do Ideb como padrão de qualidade enquanto política do Estado a ser adotada nos níveis nacional, estadual e municipal, percebe-se o distanciamento da qualidade socialmente referenciada defendida nas Conaes de 2010 e 2014. Ao priorizar o rendimento em provas de larga escala e o produto final em detrimento do processo e do contexto, caminha-se para um modelo educacional em que impera a concorrência de mercado imposta para o serviço público escolar. Numa perspectiva privatista da educação, nega-se o princípio da educação como um bem público e como política de um Estado democrático.

Nos discursos dos docentes da amostra da pesquisa percebe-se a pressão que o Ideb levou para dentro das escolas, gerando angústia e tensão por atribuir a responsabilidade pelo fracasso do ensino a esses sujeitos. Os professores reconhecem como uma das principais falhas do índice o fato dele não levar em conta o contexto socioeconômico do aluno e nem o processo de aprendizagem como um todo. Todo o trabalho desenvolvido ao longo do ano escolar é reduzido ao dia da prova. De forma geral, a maioria dos professores não reconhece o Ideb como padrão de qualidade e tampouco representa o trabalho pedagógico realizado nas escolas.

Logo, o padrão de educação de qualidade no decênio de vigência dos Planos distancia-se do padrão de qualidade defendido pelos movimentos sociais progressistas, ou seja, a concepção de qualidade socialmente referenciada. A perspectiva da educação com qualidade social, trata-se de uma qualidade negociada, que considera os fatores internos e externos à escola e que valoriza a ação dos sujeitos no processo educativo, que vai ao encontro do postulado pelos educadores em seus discursos. Esta qualidade socialmente referenciada reconhece a educação como um bem público e de direito de todos.

\section{Referências}

AFONSO, A.J. Avaliação Educacional: regulação e emancipação. - São Paulo: Cortez, 2000. AFONSO, A.J. Protagonismos instáveis dos princípios de regulação e interfaces público/privado em Educação. Educação \& Sociedade, Campinas, v. 31, n. 113, p. 11371156, out./dez. 2010.

ASSIS, L.M.de. A Avaliação e o Plano Nacional de Educação: concepções e práticas em disputa. In: DOURADO, L.F. (Org.). PNE 2014/2024: avaliação e perspectivas. 2016. (No prelo). 
ALVES, E. F.; ASSIS, L. M. Qualidade educacional e Ideb: uma análise dos Planos de Educação de Goiás e de São Luís de Montes Belos em contraponto à percepção dos professores dessa Rede Municipal de

Ensino.

AZEVEDO, J.M.L.de. Plano Nacional de Educação e planejamento: a questão da qualidade da educação básica. Retratos da Escola, Brasília, v.8, n.15, p.265-280, jul./dez. 2014.

BRASIL. Conferência Nacional de Educação. Documento Final - Conae 2014. - Brasília: Fórum Nacional de Educação, 2014a. Disponível em: <http://fne.mec.gov.br/images/doc/DocumentoFina240415.pdf>. Acesso em: 14 nov. 2016.

BRASIL. Plano Nacional de Educação 2014-2024: Lei $\mathrm{n}^{\circ}$ 13.005, de 25 de junho de 2014, que aprova o Plano Nacional de Educação (PNE) e dá outras providências. Brasília: Câmara dos Deputados, Edições Câmara, 2014b. - (Série Legislação; n. 125).

DOURADO, L.F. Plano Nacional de Educação: política de Estado para a educação brasileira. - Brasília: Inep, 2016. - (PNE em Movimento; 1).

DOURADO, L.F.; OLIVEIRA, J.F.de. A qualidade da educação: perspectivas e desafios. Caderno Cedes, Campinas - SP, v. 29, n. 78, p. 201-215, mai./ago. 2009.

FERNANDES, R. Índice de Desenvolvimento da Educação Básica (Ideb). - Brasília: Instituto Nacional de Estudos e Pesquisas Educacionais Anísio Teixeira, 2007. - (Série Documental. Textos para Discussão; 26).

FREITAS, D.N.T.de. Avaliação da Educação Básica no Brasil: características e pressupostos. In: BAUER, A.; GATTI, B.A.; TAVARES, M.R. (Orgs.). Ciclo de Debates: vinte e cinco anos de avaliação de sistemas educacionais no Brasil, origens e pressupostos. - Florianópolis: Editora Insular, 2013. (p. 70-96).

FREITAS, L.C. de. Eliminação adiada: o ocaso das classes populares no interior da escola e a ocultação da (má) qualidade do ensino. Educação \& Sociedade, Campinas, v. 28, n. 100 - Especial, p. 965-987, out. 2007.

GATTI, B.A. Possibilidades e Fundamentos de avaliações em larga escala: primórdios e perspectivas contemporâneas. In: BAUER, A.; GATTI, B.A.; TAVARES, M.R. (Orgs.). Ciclo de Debates: vinte e cinco anos de avaliação de sistemas educacionais no Brasil, origens e pressupostos. - Florianópolis: Editora Insular, 2013. (p. 47-69).

GoÍAS (Estado). Secretaria de Estado da Casa Civil. Lei no 18.969, de 22 de julho de 2015. Aprova o Plano Estadual de Educação, para o decênio 2015/2025 e dá outras providências. - Goiás, 2015.

GOIÁS (Estado). Secretaria de Estado da Educação. SAEGO 2013. Sistema de Avaliação Educacional do Estado de Goiás. Revista da Gestão Escolar. - Goiânia : Caed/UFJF, 2013.

HORTA NETO, J.L. IDEB: limitações e usos do indicador. In: BAUER, A.; GATTI, B.A.; TAVARES, M.R. (Orgs.). Ciclo de Debates: vinte e cinco anos de avaliação de sistemas educacionais no Brasil, origens e pressupostos. - Florianópolis: Editora Insular, 2013. (p. 149-161).

RICHTER, L.M.; SOUZA, V.A.; SILVA, M.V. A dimensão meritocrática dos testes estandardizados e a responsabilização unilateral dos docentes. RBPAE, v. 31, n. 3, p. 607625, set./dez. 2015.

SÃO LUÍS DE MONTES BELOS (Município). Prefeitura Municipal. Lei no $\mathbf{2 . 0 5 8}$, de 24 de junho de 2015. Dispõe sobre a aprovação do Plano Municipal de Educação de São Luís de Montes Belos e dá outras providências. - São Luís de Montes Belos, GO, 2015. 
ALVES, E. F.; ASSIS, L. M. Qualidade educacional e Ideb: uma análise dos Planos de Educação de Goiás e de São Luís de Montes Belos em contraponto à percepção dos professores dessa Rede Municipal de Ensino.

SÃO LUÍS DE MONTES BELOS (Município). Secretaria Municipal de Educação. Projeto Político-Pedagógico da Rede Municipal de Ensino 2016. - São Luís de Montes Belos, GO : SME, 2016. 
ALVES, E. F.; ASSIS, L. M. Qualidade educacional e Ideb: uma análise dos Planos de Educação de Goiás e de São Luís de Montes Belos em contraponto à percepção dos professores dessa Rede Municipal de Ensino.

\title{
JORNAL DE \\ POLÍTICAS EDUCACIONAIS \\ ISSN 1981-1969 \\ Volume 12 \\ Número 7 \\ 31 de maio de 2018
}

\begin{abstract}
(c)
SORERIGHIS RESERNED O Copyright é retido pelo/a autor/a (ou primeiro co-autor) que outorga o direito da primeira publicação ao Jornal de Políticas Educacionais. Mais informação da licença de CreativeCommons encontram-se em http://creativecommons.org/licenses/by-nc-nd/2.5. Qualquer outro uso deve ser aprovado em conjunto pelo/s autor/es e pelo periódico.

JoRnAl De Políticas EduCACionais é uma publicação do Núcleo de PolíticasEducacionaisdo Setor de Educação da Universidade Federal do Paraná - NuPE/UFPR, em consórcio com a Linha de Pesquisa em Políticas Educacionais do Programa de Pós-Graduação em Educação - PPGE/UFPR, que aceita colaboração, reservando-se o direito de publicar ou não o material espontaneamente enviado à redação. As colaborações devem ser enviadas ao NuPE/UFPR, conforme orientações contidas nas páginas do periódico na internet: http://revistas.ufpr.br/jpe.
\end{abstract}

\author{
Indexação: \\ BBE - Biblioteca Brasileira de Educação (MEC/INEP) \\ Clase (Base de Datos Bibliográfica de Revistas de Ciencias Sociales y Humanidades) \\ Diadorim - Diretório de Política de Acesso Aberto das Revistas Científicas Brasileiras (IBICT) \\ Google Scholar \\ Index Copernicus \\ Portal de Periódicos (CAPES) \\ SER - Sistema Eletrônico de Revistas da Universidade Federal do Paraná (SER/UFPR) \\ Sumários de Revistas Brasileiras (FUNPEC-RP) \\ DRJI - Directory of Research Journals Indexing
}

(Periódico integralmente disponível apenas em via eletrônica)

Jornal de Políticas Educacionais / Núcleo de Políticas Educacionais da Universidade Federal do Paraná NuPE/UFPR - v.1, n. 1 (1o semestre de 2007) - Curitiba: NuPE/UFPR.

Volume 12, número 7 - Maio de 2018

ISSN 1981-1969

1. Educação - Periódicos. 2. Política Educacional - Periódicos. I. NuPE/UFPR

Comitê Editorial:

Ângelo Ricardo de Souza (UFPR)

Ana Lorena Bruel (UFPR)

Marcos Alexandre Ferraz (UFPR)

Conselho Editorial:

Andréa Barbosa Gouveia (UFPR), Ângela Hidalgo (UNICENTRO), Cesar GernominoTello (Universidad Nacional TresFebrero, Argentina),Gladys Beatriz Barreyro (USP), Juca Gil (UFRGS), Jefferson Mainardes 
ALVES, E. F.; ASSIS, L. M. Qualidade educacional e Ideb: uma análise dos Planos de Educação de Goiás e de São Luís de Montes Belos em contraponto à percepção dos professores dessa Rede Municipal de Ensino.

(UEPG), João Ferreira de Oliveira (UFG), Luiz Souza Júnior (UFPB), Marcos Edgard Bassi (UFSC), Regina Maria Michelotto (UFPR), Robert Verhine (UFBA), Rosana Cruz (UFPI), Rubens Barbosa Camargo (USP), Sebastián Donoso Díaz (Universidad de Talca, Chile), Taís Moura Tavares (UFPR), TheresaAdrião (UNICAMP), Vera Peroni (UFRGS).

\section{Jornal de Políticas Educacionais \\ Universidade Federal do Paraná Setor de Educação}

Núcleo de Políticas Educacionais - NuPE/UFPR

Rua Gal. Carneiro, 460 - 4o andar - Sala 407/C

80.060-150 - Curitiba - PR - Brasil

Tel.: 41-3360-5380

jpe@ufpr.br

http://revistas.ufpr.br/jpe 